\title{
A Low Cost Air Hybrid Concept
}

\author{
C.Y. Lee, H. Zhao and T. Ma \\ School of Engineering and Design, Brunel University, Uxbridge, UB8 3PH - UK \\ e-mail: cho-yu.lee@brunel.ac.uk - hua.zhao@brunel.ac.uk - tomthma@yahoo.com
}

\begin{abstract}
Résumé - Un concept hybride à air et à bas prix - Le moteur hybride à air absorbe l'énergie cinétique du véhicule en cas de freinage, la stocke sous forme d'air comprimé, puis la réutilise pour faire avancer le véhicule en circulation ou en accélération. Capter, stocker et réutiliser cette énergie et créer ainsi une puissance plus importante peut donc permettre de plus grandes économies de carburant, surtout en ville et zone urbaine, lorsque les conditions de circulation imposent de nombreux arrêts et démarrages. Pour pouvoir réutiliser l'énergie cinétique, on distingue trois modes de base d'utilisation du véhicule : les modes compression (MC), expansion (ME) et standard. Un moteur hybride à air et à bas prix a été proposé et étudié. Un tel moteur peut être opéré par le biais de technologies de production, comme le VVT et la désactivation des soupapes. Dans ce travail, des analyses systématiques de performance ont été menées via des modèles dynamiques détaillés utilisant le logiciel Ricardo WAVE. Une optimisation des soupapes a été effectuée dans l'objectif d'un fonctionnement plus efficace du système et pour obtenir une pression effective moyenne de freinage plus élevée pour les modes MC et ME, respectivement.
\end{abstract}

\begin{abstract}
A Low Cost Air Hybrid Concept - The air hybrid engine absorbs the vehicle kinetic energy during braking, stores it in an air tank in the form of compressed air, and reuses it to propel a vehicle during cruising and acceleration. Capturing, storing and reusing this braking energy to give additional power can therefore improve fuel economy, particularly in cities and urban areas where the traffic conditions involve many stops and starts. In order to reuse the residual kinetic energy, the vehicle operation consists of 3 basic modes, i.e. Compression Mode (CM), Expander Mode (EM) and normal firing mode. Unlike previous works, a low cost air hybrid engine has been proposed and studied. The hybrid engine operation can be realized by means of production technologies, such as VVT and valve deactivation. In this work, systematic investigation has been carried out on the performance of the hybrid engine concept through detailed gas dynamic modelling using Ricardo WAVE software. Valve timing optimization has been done for the more efficient operation of air hybrid operation and obtaining higher braking and motoring mean effective pressure for CM and EM respectively.
\end{abstract}




\section{INTRODUCTION}

While the traffic conditions involve frequent vehicle stops and starts, a large amount of fuel is needed to accelerate the vehicle, and some of this is converted to heat in brake friction during deceleration. However, a dramatic amount of fuel can be saved by using the momentum of the vehicle during coasting and deceleration to drive an air compressor so that the compressed air can be stored and later used to power the vehicle during cruising and acceleration.

In the previous proposed air hybrid concepts [1-8], the air hybrid operation requires the use of fully variable valve actuation systems, weather it is electromechanical, hydraulic, or pneumatic camless system. Simulations made by Tai et al . [1] show round-trip efficiency of $36 \%, 38 \%$ reduction in fuel consumption and $64 \%$ fuel economy improvement. Trajkovic et al. [8] made real engine experiments show a regenerative efficiency of $40-48 \%$ has been achieved. However, such complex camless systems are limited to research engines and they are unlikely to be suited for production in the short term. In this work, an alternative air hybrid concept with production technologies has been proposed and analysed. In this concept, a Cam Profile Switching system (CPS) is utilized to control an intake valve in each cylinder to operate the engine as an air compressor or an air expander, in conjunction with an one-way valve in the intake port and an external air tank valve.

A Ford PUMA 2 Litre diesel engine has been modelled as an air hybrid engine by using Ricardo's WAVE software, which is an engine simulation tool to model the gas dynamics and engine performance.

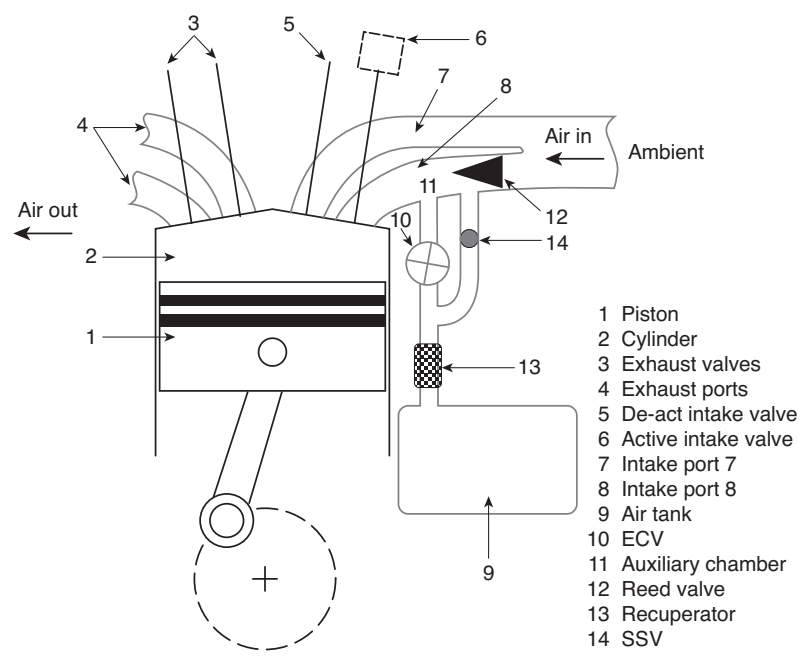

Figure 1

Air hybrid engine with a reed valve inside the intake port schematic.

\section{CONFIGURATION OF THE AIR HYBRID ENGINE}

Figure 1 shows an air hybrid engine having a piston (1) reciprocating in a cylinder (2). Intake valves (5 and 6) connect the cylinder with intake ports ( 7 and 8 respectively) and exhaust valves (3) connect the cylinder with exhaust ports (4). Active intake valve (6) is timed to open and close by a CPS system. A non-return reed valve (12) is additionally provided in the intake port (8) connected to the active intake valve (6). While air pressure (inside the auxiliary chamber) is lower than atmosphere pressure, the reed valve pedals open and air is induced into intake port (8). On the other hand, the reed valve pedals close and air can be kept without escaping out of intake port (8) to atmosphere while the air pressure (inside the auxiliary chamber) is higher than atmosphere pressure.

An air tank (9), stores high-pressure air, connected to intake port (8) through a recuperator (13) and an Energy Control Valve (ECV) into an auxiliary chamber (10 and 11 respectively). Recuperator (13), made of a ceramic matrix could absorb and store heat energy when compressed air is stored from cylinder to air tank in CM. It also releases heat energy while releasing compressed air from air tank to cylinder in EM. Therefore, high temperature and high pressured compressed air could be reused. In the simulation, only the heat transfer coefficient of the air tank has the value of 0.0 imply that there is no heat loss in the length of the air tank. Therefore, recuperator (13) is not modelled separately in the analysis but the compressed air will be assumed to retain their temperature in the air tank which is equivalent to $100 \%$ recuperator efficiency. A solenoid valve has been adopted to be the ECV 10 that controls air flow out of the air tank for EM. On the contrary, a check valve has been adopted to be the SSV (Self-Sealing Valve) (14) that controls air flow in of the air tank for CM.

The engine also includes three more cylinders, a fuel system and an ignition system which are not shown in Figure 1 for highlighting the main subject of the present study.

\section{THE PRINCIPLE OF OPERATION}

Figure 2 shows the valve timing diagrams for the normal firing mode, CM and EM. During the normal firing mode, both intake and exhaust valves operate at their default values. During deceleration and braking, the opening of the active intake valve takes place during the normal compression stroke of the four-stroke cycle so that the air is compressed and stored in the auxiliary chamber formed by the one-way Reed Valve, the SSV and the ECV so that engine braking is realised. The engine is turned into an air expander by opening the ECV and active intake valve during the normal intake stroke so that high pressure air forces the piston down and generate the motoring work. 


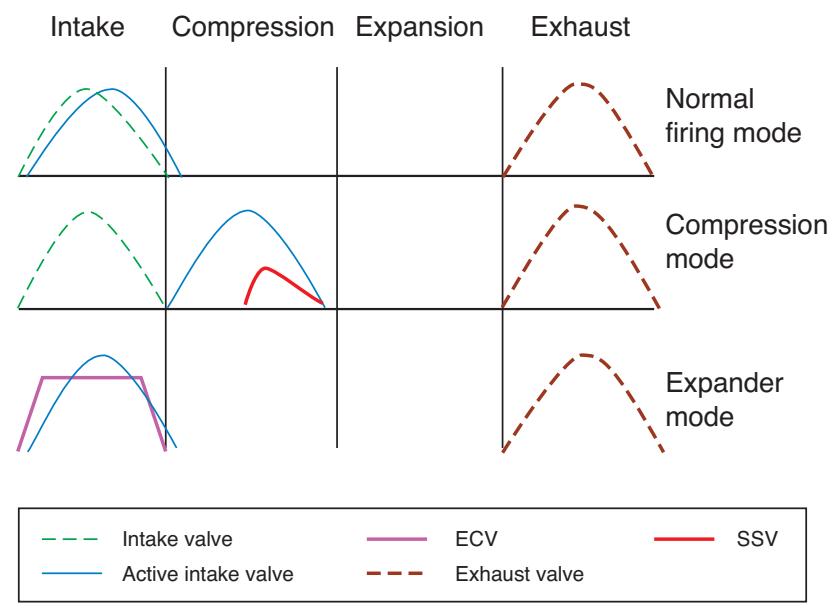

Figure 2

Engine valves, active intake valve and ECV timing for normal firing mode, $\mathrm{CM}$ and $\mathrm{EM}$.

The key feature of this new concept is the auxiliary chamber and the ECV acting as a buffer between the engine cylinder and the air storage tank.

The size of the auxiliary chamber volume is an important parameter in this concept. It is determined by the position of the non-return reed valve, the position of the SSV and the position of the ECV. The geometric compression ratio of the engine is 18.4:1 for a CI engine in the normal firing mode (the engine displacement volume and clearance volume are $500 \mathrm{~cm}^{3}$ and $28.7 \mathrm{~cm}^{3}$ per cylinder respectively). However, when the engine is switched to the compression mode, the actual compression ratio $\left(R_{c}\right)$ decreases as the volume of the auxiliary chamber is included in the cylinders' total clearance volume. For the auxiliary chamber volume of $67.7 \mathrm{~cm}^{3}$ examined below, the actual compression ratio is calculated as:

$$
R_{c}=\frac{500+28.7+96.4}{28.7+96.4}=5.0: 1
$$

During CM, air is compressed into the auxiliary chamber isolated by the ECV and the SSV from the air storage tank, and then released by the SSV into the air storage tank due to the pressure difference between the auxiliary chamber and the air storage tank. During EM, the ECV controls the amount of compressed air released from the air storage tank to the auxiliary chamber and then goes into the cylinder after the intake valve is opened.

Without the auxiliary chamber and ECV, the intake valve has to be able to vary its opening profile in order to control the amount of compressed air released from the air storage tank. By adopting the auxiliary chamber and the ECV, the complicated and expensive active valve control system could be avoided in the engine design. For example, the valve actuation system has been adopted with a camless hydraulic valve actuator system in recent research [7-8].

\section{SIMULATION AND RESULTS}

\subsection{Engine Simulation Setup}

The modelled air hybrid engine was based on a Ford PUMA $2 \mathrm{~L}$ diesel engine with four cylinders and the air hybrid operation was simulated in Ricardo's WAVE software. The simulation analyzes the dynamics of pressure waves, mass flows, and energy losses in ducts, plenums, and the manifolds of the engine. Engine and valves data are given in Table 1 and Table 2 respectively. A 40 Litre air tank has been used in this model. Its pressure range is between 5 and 20 bar in the simulation.

TABLE 1

Engine dimensions and characteristics

\begin{tabular}{c|c}
\hline Number of cylinders & 4 \\
\hline Cylinder bore & $86 \mathrm{~mm}$ \\
\hline Piston stroke & $86 \mathrm{~mm}$ \\
\hline Connecting rod length & $160 \mathrm{~mm}$ \\
\hline Displacement volume & $500 \mathrm{~cm}^{3}$ \\
\hline Clearance volume & $28.7 \mathrm{~cm}^{3}$ \\
\hline Total volume of one cylinder & $528.7 \mathrm{~cm}^{3}$ \\
\hline Compression ratio & $18.4: 1$ \\
\hline$R_{c}$ for air hybrid mode & (a) $5.0: 1$ \\
\hline
\end{tabular}

Compressed Air Transfer Coefficient (CATC) has been introduced to indicate the efficiency of the air hybrid braking process. It is defined as the ratio of air mass transferred to the air tank from the cylinder to air mass transferred to the cylinder from the atmosphere, as given by Equation (2):

$$
\operatorname{CATC}_{b}=\frac{m_{\text {air }, g t}}{m_{\text {air, in }}}
$$

and it is a measure of the fraction of the vehicle's kinetic energy which can be stored in the air reservoir in the form of potential energy.

The potential of work of each unit of air mass captured during the compression mode is described by the braking specific indicated mean effective pressure $\left(\right.$ imep $_{\mathrm{b}}$ ), which is the ratio of imep and air mass transferred to the air tank:

$$
\text { Specific imep } \mathrm{b}_{\mathrm{b}}=\frac{\left|\mathrm{imep}_{\mathrm{b}}\right|}{m_{a i, g t v}}
$$

The output of work per unit mass during the expansion mode is represented by the motoring specific indicated mean effective pressure (imep $\mathrm{p}_{\mathrm{m}}$ ):

$$
\text { Specific imep } \mathrm{m}_{\mathrm{m}}=\frac{\text { imep }_{\mathrm{m}}}{m_{a i r, g t v}}
$$


TABLE 2

Valves dimensions and characteristics

\begin{tabular}{c|c}
\hline Intake valve & 2 \\
\hline Diameter & $23.5 \mathrm{~mm}$ \\
\hline Opening point (normal) & $20^{\circ} \mathrm{BTDC}$ \\
\hline Closing point (normal) & $60^{\circ} \mathrm{ABDC}$ \\
\hline Maximum lift & $8.75 \mathrm{~mm}$ \\
\hline Exhaust valve & 1 \\
\hline Diameter & $23.4 \mathrm{~mm}$ \\
\hline Opening point & $60^{\circ} \mathrm{BBDC}$ \\
\hline Closing point & $35^{\circ} \mathrm{ATDC}$ \\
\hline Maximum lift & $8.75 \mathrm{~mm}$ \\
\hline Reed valve & 1 \\
\hline Pedal stiffness & $1900 \mathrm{~N} / \mathrm{m}$ \\
\hline Maximum lift & $9 \mathrm{~mm}$ \\
\hline ECV count & 1 \\
\hline Diameter & $24.9 \mathrm{~mm}$ \\
\hline
\end{tabular}

Furthermore, the regenerative efficiency is represented by the ratio of the motoring specific imep and braking specific imep:

$$
\eta_{\text {regen }}=\frac{\text { Specific imep }_{\mathrm{m}}}{\text { Specific imep }_{\mathrm{b}}}
$$

\subsection{Active Intake Valve Shifting and ECV Opening Timing for CM}

The optimum control of the compression work is to find the best active intake valve closing timing for maximum braking performance, as defined by the calculated Compressed Air Transfer Coefficient (CATC), and braking work obtained.

$\mathrm{CATC}_{\mathrm{b}}$ depends on the gas dynamics of the intake system and the auxiliary chamber. Figure 3 shows that maximum $\mathrm{CATC}_{\mathrm{b}}$ is realized when the active IVC is at $50^{\circ} \mathrm{ATDC}$ with IVO at $30^{\circ} \mathrm{BBDC}$. The active intake valve closing at $50^{\circ}$ ATDC prevents backflow of the compressed air, providing maximum air transfer efficiency. For earlier IVCs, it has not enough time to accumulate compressed air from cylinders to the tank due to short opening duration (from TDC to IVCs). On the other hand, very late IVC timings results in more compressed air flowing back into the cylinder and wasted. Furthermore, CATC $_{\mathrm{b}}$ is higher at low tank pressure because at lower back pressure the more inducted air can be compressed in to the tank.

Figure 4 shows the predicted variation of $i_{\text {mep }}$ (shown the absolute values) in regard to active IVC points for the tank pressure range between 5 and 20 bar, at intervals of

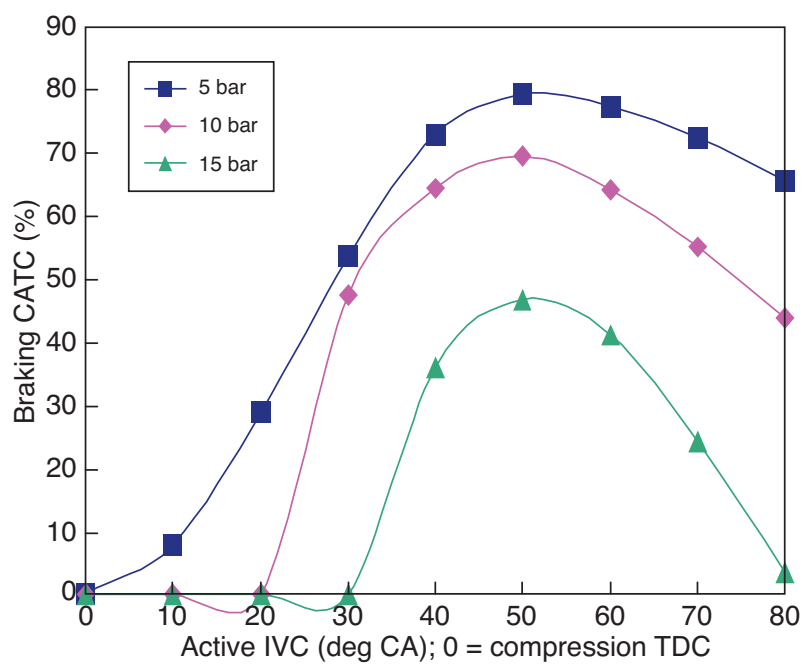

Figure 3

Predicted $\mathrm{CATC}_{\mathrm{b}}$ for 2000 rpm engine speed.

5 bar. It can be seen from the results that high braking performance is achieved for a range of active IVC timings between $40^{\circ}-60^{\circ} \mathrm{CA}$ ATDC, where increased imep $_{\mathrm{b}}$ (and hence braking torque) is realized. Imep $\mathrm{p}_{\mathrm{b}}$ drops rapidly if IVC is shifted out of the above range, while peak imep $_{b}$ is achieved at $50^{\circ} \mathrm{CA}$, regardless the tank pressure. It should note that the actual braking torque exerted to the vehicle will include the frictional torque and hence the braking bmep will be typically 1 bar above the values shown in Figure 4 .

However, braking specific imep (braking imep per unit of induced air mass compressed in to the tank) shows the energy capture and storage ability. Smaller braking specific imep shows higher energy capture and storage ability. Figure 5 shows the best energy capture and storage ability happens at $60^{\circ}$ active IVC and $80^{\circ}$ active IVC for 15 bar tank pressure and the tank pressure between 5 bar and 10 bar respectively. The peaks in the braking specific imep values are caused by the least amount of air compressed into the air tank at very early or very retarded IVC timings.

The predicted cylinder indicator diagrams for various valve lift profile shifts are shown in Figure 6 at $2000 \mathrm{rpm}$ engine speed and 5 bar tank pressure. In Figure 6, the much higher peak cylinder pressure shows while active IVC point is at $30^{\circ}$ ATDC due to the advanced active IVC during the compression stroke. For active IV closing at $50^{\circ}$ ATDC, the bigger Area B, comparing to Area A and Area C, reflects higher imep . $_{\text {. }}$

Based on the above investigation, Figure 7 shows optimal active intake valve and check valve timing in the same diagram together with engine valve timing. For a simple CPS system, closing time of Active intake valve is fixed at $60^{\circ}$ ATDC at any tank pressures. 


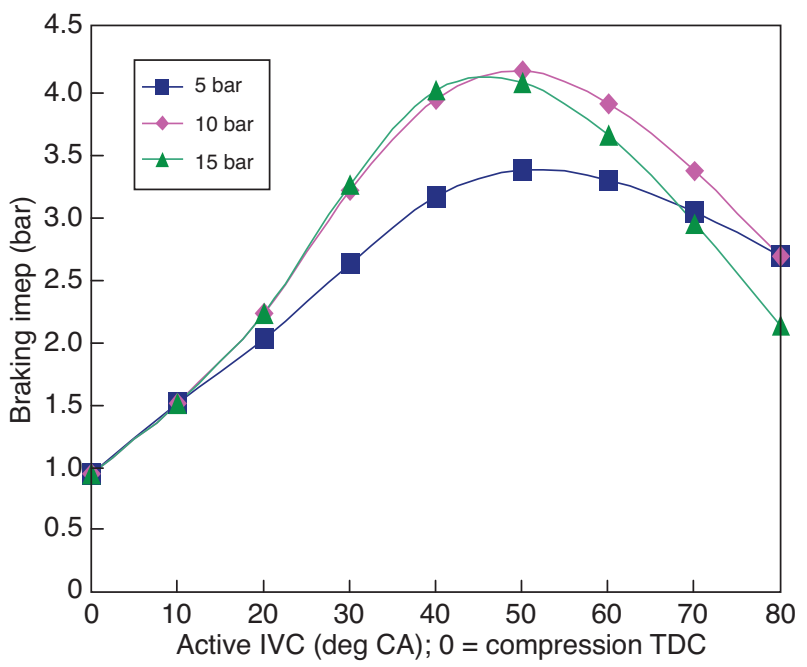

Figure 4

Predicted imep $_{\mathrm{b}}$ for $2000 \mathrm{rpm}$ engine speed.

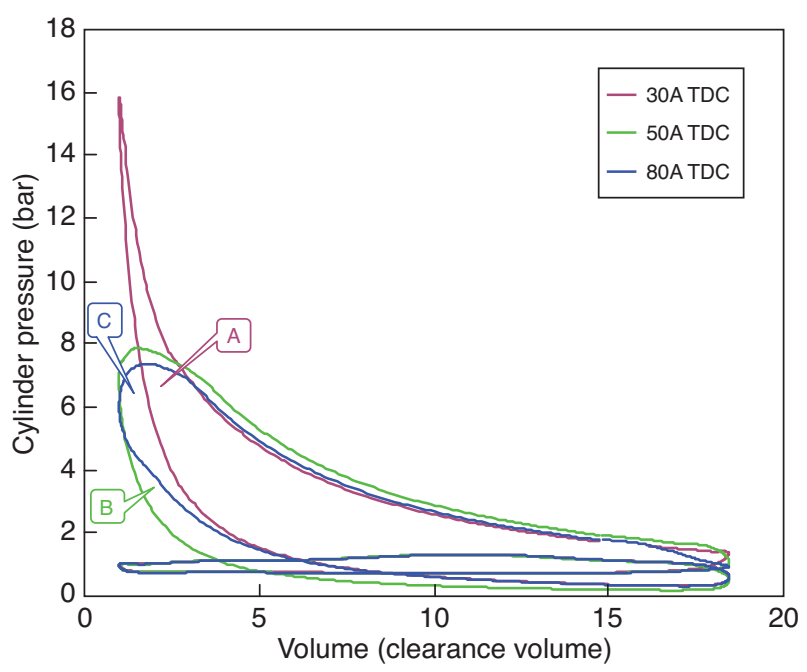

Figure 6

Indicator diagram for various active IVC timings.



Figure 5

Braking specific imep for 2000 rpm engine speed.



Figure 7

Optimal active intake valve timing for air compressor mode.

\subsection{Valves Timing Optimization for EM}

During EM, air is released by the ECV after the active intake valve is opened, and the quantity of air is controlled by ECV close timing while the active intake valve stays open and the air in the auxiliary chamber expands into the engine cylinder. To prevent compressed air from escaping, Intake valve (5) is deactivated in the intake stroke.

Although, as more compressed air expands in cylinders higher motoring work will be produced, some of the air could be wasted if the expansion process is incomplete. The amount of air should be controlled to produce a full expansion process through the optimisation of ECV timings. Therefore, the aim of optimised EM operation is to generate the highest values of power per unit mass by finding the best ECV closing timing through modelling its timing shift.

The sensitivity of predicted mass of air transferred during one engine cycle to ECV closing points for various air tank pressures is shown in Figure 8. The ECV opening point is fixed at compression TDC. It can be seen that compressed air expenditure increases for longer ECV opening duration till the end of BDC. 


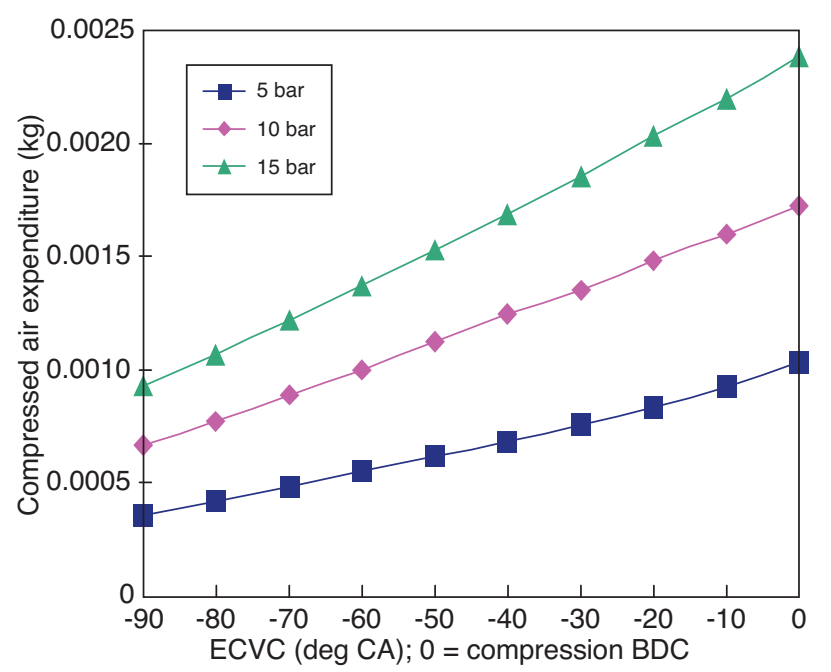

Figure 8

Compressed air expenditure for 2000 rpm engine speed.

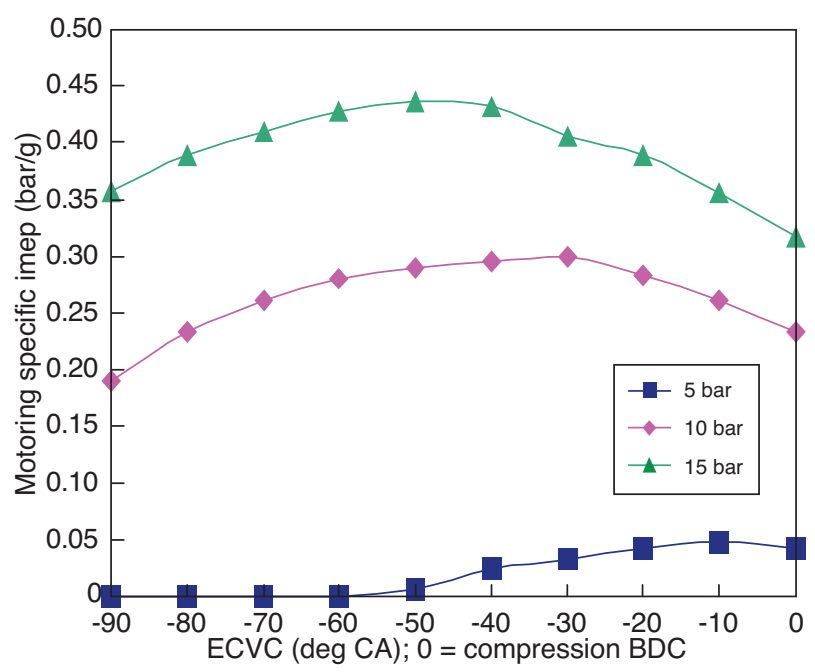

Figure 10

Motoring specific imep for $2000 \mathrm{rpm}$ engine speed.



Figure 9

Predicted imep $\mathrm{p}_{\mathrm{m}}$ for $2000 \mathrm{rpm}$ engine speed.

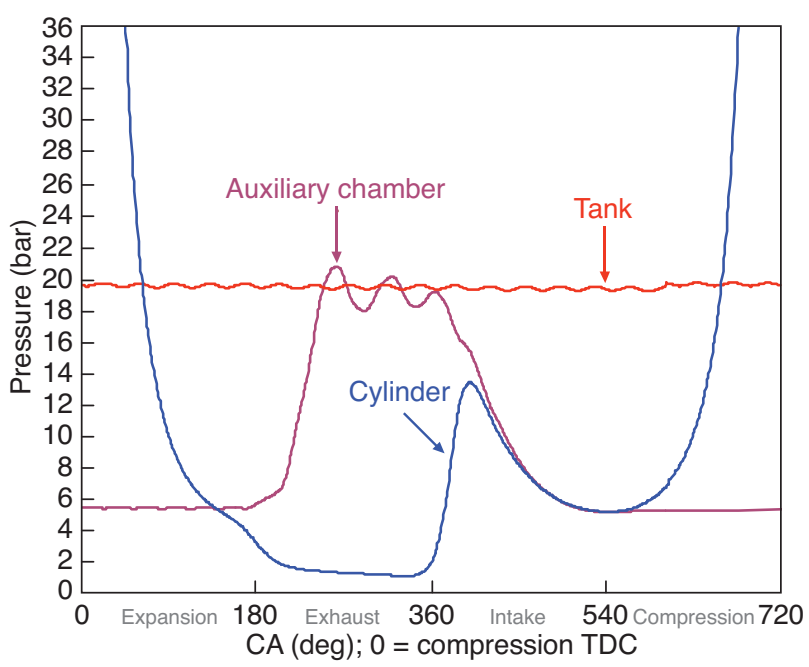

Figure 11

Pressure diagram for air expander mode.
Figure 9 shows the sensitivity of the predicted imep $_{m}$ to ECV closing points for various air tank pressures. It can be seen that ime $\mathrm{p}_{\mathrm{m}}$ is a strong function of air tank pressure and proportional to it. Imep $\mathrm{m}_{\mathrm{m}}$ increases for retarded ECV closings. However, the ratio of compressed air expenditure to imep $_{\mathrm{m}}$ practically represents the ability of the air expander which is shown in Figure 10. For various air tank pressures and ECV closing points, higher motoring specific imep indicates that compressed air is more efficiently consumed when $\mathrm{ECV}$ closes at $10^{\circ}, 30^{\circ}$ and $50^{\circ} \mathrm{BBDC}$ for 5,10 and 15 bar tank pressures respectively.

Figure 11 shows that, with intake valve 5 deactivated, cylinder pressure remains at 5 bar for the optimised ECV timing at the bottom of the real expansion process which corresponds to the intake stroke in the normal firing mode. Ideally, the final state at the end of the expansion process should reach ambient pressure for maximum expansion work. Otherwise, remaining high pressure air will cause negative work during the subsequent compression stroke. Therefore, it could be advantageous to open the intake valve (5) near the end of the expansion to relief pressure built up in the cylinder during the subsequent compression stroke.

Through systematic studies, it was found that when the opening timing of Intake valve (5) shifts to $110^{\circ} \mathrm{BBDC}$ at the expansion process (the normal intake stroke), cylinder 


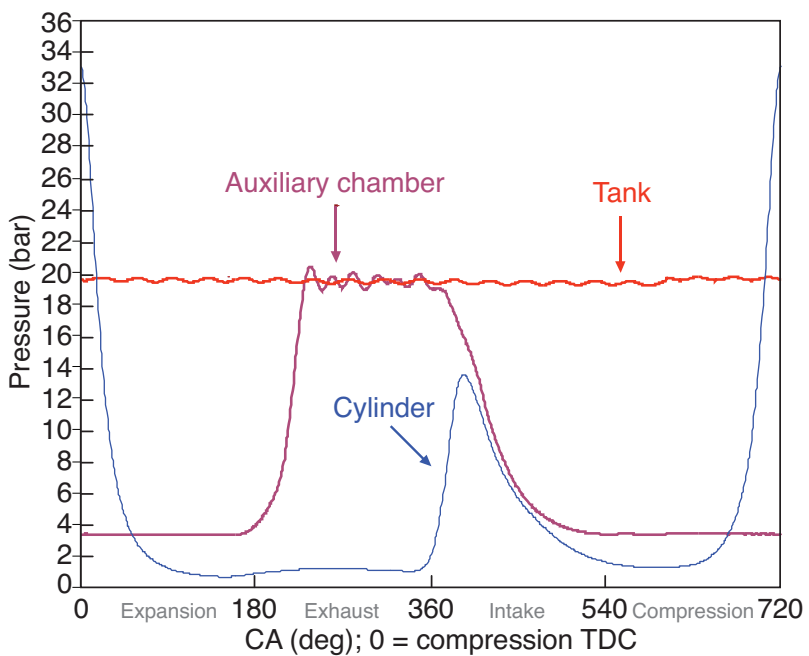

Figure 12

Pressure diagram for air expander mode (without deactivating Intake valve 5).

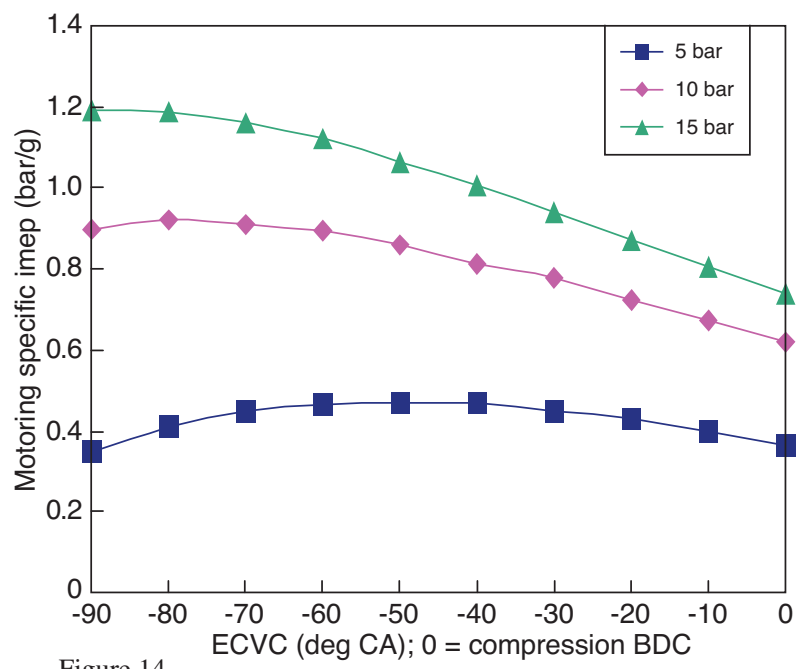

Figure 14

Motoring specific imep for $2000 \mathrm{rpm}$ engine speed (without deactivating Intake valve 5).

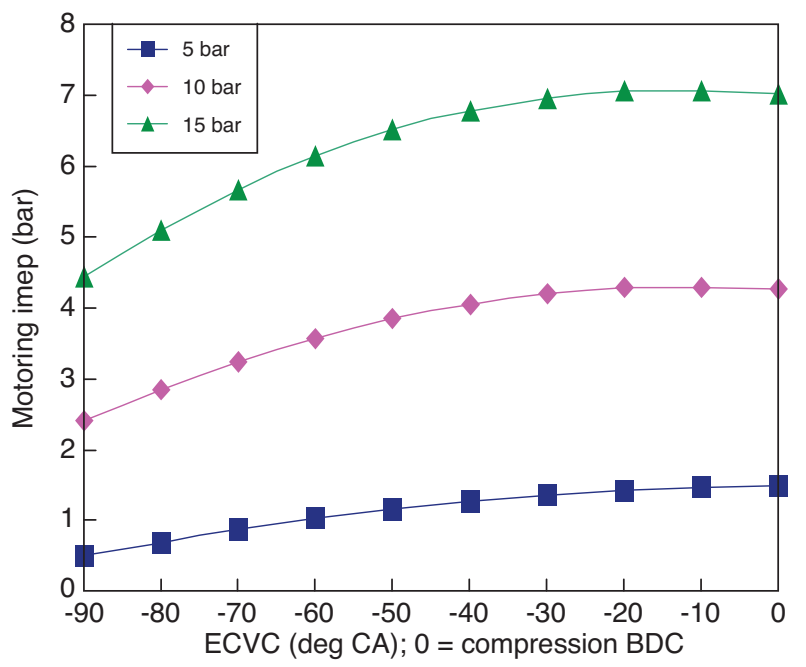

Figure 13

Predicted imep $_{\mathrm{m}}$ for $2000 \mathrm{rpm}$ engine speed (without deactivating Intake valve 5).

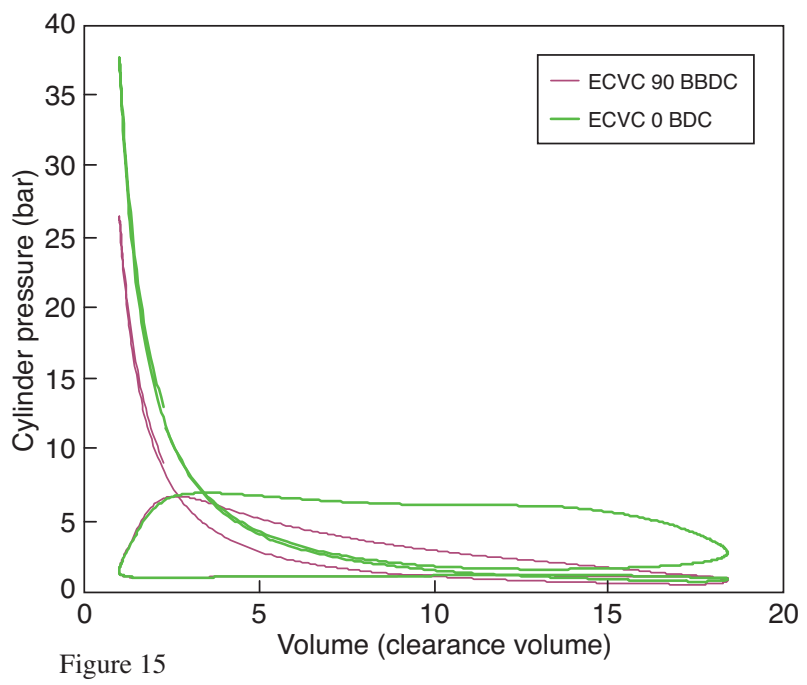

Indicator diagram for various ECVC timing. pressure decreases to the ambient pressure at the end of the real expansion process as shown in Figure 12. Because of the reduced negative work and full expansion, much higher motoring imep $_{m}$ values are generated. This is confirmed by comparing results in Figure 9 and Figure 13. At 10 bar tank pressure, the maximum motoring imep is increased from 1.7 bar to 4.3 bar, and at 15 bar tank pressure it is increased from 3.2 bar to 7.1 bar.

Because the amount of compressed air expenditure is controlled by ECV closing timing, opening of Intake valve 5 at $110^{\circ} \mathrm{BBDC}$ at the intake stroke doesn't affect its values. Figure 14 shows that higher motoring specific imep obtained when ECV closes at $40^{\circ}, 80^{\circ}$ and $90^{\circ} \mathrm{BBDC}$ for 5,10 , and
15 bar tank pressures respectively. Comparing Figures 10 and 14, maximum motoring specific imep values are increased by more than $120 \%$.

Figure 15 shows the predicted cylinder indicator diagrams for various ECV lift profiles at $2000 \mathrm{rpm}$ engine speed and 10 bar tank pressure. In Figure 15, the much higher peak cylinder pressure shows while ECVC point is at BDC, comparing to ECVC point is at $90 \mathrm{BBDC}$, because the much bigger overlap between the active intake valve lift profile and the ECV lift profile released more compressed air into the auxiliary chamber and the cylinder and then generating higher peak cylinder pressure during compression stroke. 


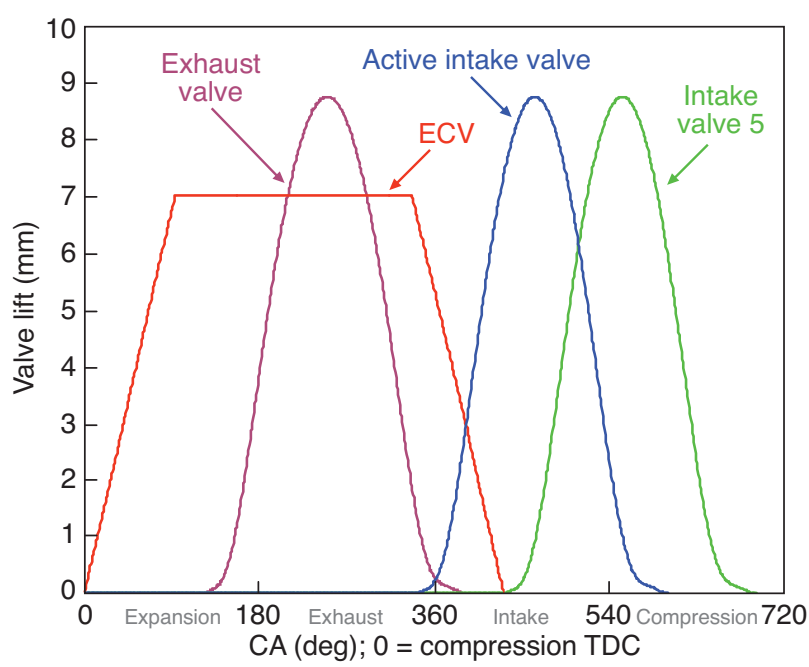

Figure 16

Optimal ECV timing for air expander mode.

Finally, Figure 16 shows the optimal ECV timing and Intake valve (5) timing according to the above investigation. The exhaust and active intake valve timings are also shown in the same diagram. While tank pressure works between 10-15 bar, ECV closing timing could be fixed at $80^{\circ}$ BBDC.

\section{CONCLUSION}

A low cost air hybrid engine concept has been proposed and analysed. The concept can be realised with current production technologies and it does not require the use of camless technologies that other air hybrid engine concepts mandate. Both compression mode and expansion mode operations can be effectively operated with the use of VVTs on the intake valves and external solenoid valves for transferring the compression air between the cylinders and the air tank.

Analytical studies have shown that valves timings have significant effects on the performance of compression mode and expansion mode operations in the proposed air hybrid concept. The closing timing of the active intake valve can be optimised for maximum braking work, while the closing timing of the ECV valve determines the expansion work during the expansion mode operation. The ECV adopts a solenoid
TABLE 3

Regenerative efficiency for 2000 rpm engine speed

\begin{tabular}{c|c|c|c}
\hline $\begin{array}{c}\text { Air tank } \\
\text { pressure }\end{array}$ & Imep $_{\mathrm{b}}$ & Imep $_{\mathrm{m}}$ & $\begin{array}{c}\text { Regenerative } \\
\text { efficiency }\end{array}$ \\
\hline 5 bar & 2.4 & 0.47 & 19.58 \\
\hline $10 \mathrm{bar}$ & 3.56 & 0.92 & 25.84 \\
\hline $15 \mathrm{bar}$ & 5.4 & 1.19 & 22.04 \\
\hline
\end{tabular}

valve which is very easy to control opening and closing timing. Positions of reed valves and the ECV also decide auxiliary chamber volume which affects its performance.

Table 3 shows a regenerative efficiency of $22-25 \%$ has been achieved while tank pressure works between 10-15 bar. However, this concept of the air hybrid engine is very simple structure. Both intake valves adopt a CPS system. The tank, reed valves and a recuperator are also low cost.

\section{REFERENCES}

1 Tai C., Tsao T. (2003) Using Camless Valvetrain for Air Hybrid Optimization, SAE paper 2003-01-0038.

2 The University of California, "UCLA Study Suggests Air Hybrid Car Could Improve Fuel Efficiency", obtained from http://www.newsroom.ucla.edu/page.asp?id=4420, last visited March 2007.

3 Schechter M. (1999) New Cycles for Automobile Engines, SAE paper 1999-01-0623.

4 Schechter M. (2000) Regenerative Compression Braking a Low Cost Alternative to Electric Hybrids, SAE paper 2000-01-1025.

5 Turner J., Bassett M., Pearson R., Picher G., Douglas K. (2004) New Operating Strategies afforded by Fully Variable Valve Trains, SAE paper 2004-01-1386.

6 Turner J., Pearson R., Kenchington S.A. (2005) Concepts for Improved Fuel Economy from Gasoline Engines, Int. J. Engine Res. 6, 2, 137-157.

7 Trajkovic S., Tunestal P., Johansson B. (2008) Investigation of Different Valve Geometries and Valve Timing Strategies and their Effect on Regenerative Efficiency for a Pneumatic Hybrid with Variable Valve Actuation, SAE paper 08SFL-0329.

8 Kang H., Tai C., Smith E., Wang X., Tsao T., Stewart J., Blumberg P. (2008) Demonstration of Air-Power-Assist (APA) Engine Technology for Clean Combustion and Direct Energy Recovery in Heavy Duty Application, SAE paper 2008-01-1197.

Final manuscript received in June 2009 Published online in February 2010 